\title{
Certification for Responsible Restoration
}

$\mathrm{T}$ here has been much debate in recent years over the question of how to achieve high standards in restoration programs. This debate has touched on many areas including the selection of model ecosystems, the definition of indices of ecosystem function, and the integration of disciplines needed to achieve these goals. I would like to suggest that one way to resolve the question of standards is to focus not only on the ecosystems being restored, but also on the individuals carrying out the restorations. The best way to do this is to establish where the responsibility for defining and executing the aims and objectives of a restoration program lie; in order to achieve this we need to provide a means of professional certification.

Before you throw your copy of REMN away in disgust, let's consider the alternatives.

How might we know when a restoration has been successful? Taking a simple case, if the intention is to, say, re-introduce an extirpated species, then the measure is fairly straightforwardcount heads. If, however, the intention is to restore a functionally and structurally complete replica of a previously existing systemsay, an oak-hickory forest-then there is a problem.

The problem is that defining standards for such a project transcends the scope of any of the traditional disciplines. A typical restoration project is likely to involve, for example, a civil engineer, hydro-geologist, a forester and an accountant. Who, then, has the final say, as to whether the project is successful? Is it the civil engineer, who seeing some beautifully regraded slopes feels a deep sense of satisfaction, yet is miffed when it is pointed out that the "soils" on the surface are in fact no more than highly compacted stored topsoils, or uncompacted "soil-forming" materials? Or the hydrologist, who can move water deposited by anything from a light spring shower to a heavy winter storm event off the site with a minimum of erosion, but who is unaware that the water so removed fails to infiltrate and recharge aquifers essential for long-term regrowth of trees? Or what about the forester who can plant 10,000 trees a day in perfect rows, the resulting "forest" looking like columns of soldiers marching across the landscape to some battle over the next ridge. (Many may die en route.) Or the accountant who points to the financial viability of a site in real estate terms, but who, when the question of whether biological diversity has been compromised arises, can only reply through gritted teeth: "It's worse than that. It's dead, Jim."

The problem, in other words, lies not with the state of knowledge, but rather in the fact that no discipline is competent to deal with all the issues involved. This is why certification of restorationists is essential, and must reflect many years of study, prac- tice and examination, backed by a professional body with moral and legal liabilities and procedures.

The route to such certification would have to be arduous, and should include:

- An undergraduate degree in an appropriate discipline, with grades achieved above a minimum standard, including work in the field with an experienced restoration practitioner.

- A graduate degree from a licensed program, validated by a professional body such as SER, and including a "Part I" examination covering all relevant disciplines.

- Two to three years of professional experience combined with part-time college attendance culminating in a "Part II" examination demonstrating competence in all relevant disciplines.

Obviously, such a program would have to be developed and administered by a professional body or institute, with appropriate legal status; SER and the New Academy may well fulfil this role. The disciplines represented would have to include geology, civil engineering, hydrology, ecology, design, humanities, economics, the law and management. Such a program would not guarantee that the certified restorationist is an expert in all of these fields, but would ensure an ability to work with others across disciplinary lines, and would also provide a way for restorationists with a special interest in any of these disciplines to "top-up" for certification or registration in specialty areas, much as physicians, attorneys, accountants and other professionals now do.

With a program of this kind in place it would be possible to stop passing the buck and to identify the individual who has the ultimate responsibility for ensuring that the best possible job has been done. Of course there would be problems and trade-offs in such an endeavor, many of which have been discussed at SER meetings over the years. But this should not prevent us embarking upon such a program.

Of course these comments are no more than a starting point for debate, but a debate that I feel that we should embark upon soon, vigorously, and in a spirit of inclusiveness. We need to include colleagues from the all professions with roles or interests in the restoration of land, if we are to stand any chance of making our vision of repairing a damaged planet a reality.
Jim Harris, Professor
Department of Environmental Sciences and Mathematics
University of East London, Romford Road
London E15 4LZ, United Kingdom
Tel: 44-81-590 7722 ext. 4076 